\title{
In vivo studies of articular tissue damage mediated by catabolin/interleukin 1
}

\author{
J T DINGLE, D P PAGE THOMAS, B KING, AND D R BARD \\ From the Strangeways Research Laboratory, Worts Causeway, Cambridge
}

SUMMARY A partially purified porcine synovial catabolin interleukin $1\left(C_{F}\right)$ preparation was injected intra-articularly into rabbit stifle (knee) joints. Radiolabelled $C_{F}$ was rapidly cleared from the joint $(0.4 \mathrm{~h})$. Repeated injections of $C_{F}$ caused a marked loss of articular cartilage glycosaminoglycan (GAG) and a great increase in synovial fluid GAG. ${ }^{35} \mathrm{SO}_{4}$ uptake was inhibited. Time course experiments after a single injection produced similar loss of GAG from knee cartilages, which was maximal three days after injection. The above changes were significantly less with heat inactivated preparations. Loss of articular cartilage metachromasia was found histologically, and an acute synovitis occurred together with lymphocytic foci and plasma cell infiltration.

Key words: glycosaminoglycan, ${ }^{35} \mathrm{~S}$ uptake, cartilage matrix degradation, synovial inflammation, IL1, catabolin.

Currently the role of locally produced cytokines of the interleukin 1 (IL1) family in the pathogenesis of articular diseases is the subject of much speculation. Catabolin/IL1-like activity is both synthesised and secreted from a variety of connective tissues and cells of human and animal origin maintained in culture $^{1-3}$; substantial activity has also been shown in a study of human rheumatoid synovial tissue. ${ }^{4}$ The action of porcine synovial catabolin/IL1 and porcine leucocyte IL1 on cartilage and bone in organ culture has been extensively studied..$^{5-7}$ Porcine leucocyte IL1 ( $\alpha$ and $\beta$ forms) has been purified to homogeneity, ${ }^{8}$ and porcine synovial catabolin/IL1 has been substantially purified. It is well recorded that these cytokines can induce living chondrocytes to degrade connective tissue macromolecules in vitro rapidly and extensively. In recent studies it was shown that these porcine cytokines will also inhibit the synthesis of cartilage extracellular macromolecules, e.g., ${ }^{35} \mathrm{SO}_{4}$ incorporation into proteoglycan and collagen biosynthesis. ${ }^{9} 10$ These findings may be of some significant importance in the long term action of such messengers, if indeed they do function in vivo.

It seems likely that the porcine leucocyte and synovial cytokines are analogues of human interleukin. ${ }^{1-14}$ Whatever the degree of interrelationship between the activities of these various

Accepted for publication 10 February 1987.

Correspondence to Dr D P Page Thomas, Strangeways Research Laboratory, Worts Causeway, Cambridge CB1 4RN. messengers, suggestions have been made, based entirely on the in vitro work, that they have a role in cartilage and bone erosions in vivo, in human diseases such as osteoarthritis and rheumatoid arthritis. ${ }^{15-17}$ There has been no published work to date on the action of the cytokines on the integrity of articular tissues in vivo.

The work presented below is a preliminary investigation of the action of partially purified synovial catabolin/IL1 $\left(\mathrm{C}_{\mathrm{F}}\right)$ on joint tissues when given intra-articularly. Changes in cartilage catabolism and synthetic activity were found together with inflammatory changes in the synovium.

\section{Materials and methods}

Old English rabbits (2-3 kg) were used throughout. Partially purified porcine synovial catabolin/IL1 $\left(C_{F}\right)^{18}$ was labelled with ${ }^{131}$ I using Iodobeads (Pierce Chemical Co, Rockford, Illinois) according to Markwell. ${ }^{19}$ After the reaction of carrier sodium iodide was added to give a final concentration of 100 $\mathrm{mg} / \mathrm{ml}$, and the solution was dialysed for $72 \mathrm{~h}$ in two changes of deionised water and a third of physiological saline. All these procedures were performed at $4^{\circ} \mathrm{C}$. The final product had an activity of $6 \mathrm{MBq} / \mathrm{mg}$ protein. The filter sterilised preparation was then injected intra-articularly into the knees of four rabbits who had been previously sedated with 'Hypnorm' $(0.4 \mathrm{ml} / \mathrm{kg})$ (Jannsen Pharmaceuticals, Beerse, Belgium). The rabbits were then positioned rapidly with their knees underneath vertical, lead 
collimated gamma scintillation probes and the radioactivity measured as previously described. ${ }^{20}$ Counting was repeated at intervals up to $24 \mathrm{~h}$.

In the experiment to determine in vivo catabolic action of the cytokine preparation a group of five rabbits was injected with $C_{F}$ and heat inactivated $C_{F}$ $\left(10 \%\right.$ of the activity of $C_{F}$ when tested in the organ culture bioassay) into each of their knees in a

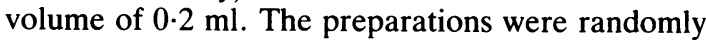
allocated to the left and right knees, and the injections were repeated daily for seven days. Two further rabbits were used as sham operated controls. In each of these animals one knee was 'needled' and the other was injected with $200 \mu \mathrm{l}$ of physiological saline. Twenty four hours after the last injection the animals were killed by an intravenous injection of 'Euthatal' (May and Baker, Dagenham, Essex). The suprapatellar pouches of the knee joints were opened and any visible fluid sucked out and saved. The joint was washed with $0.2 \mathrm{ml}$ physiological saline in two aliquots. The fluids and washings were bulked and frozen until assayed for glycosaminoglycan. Cartilage slices were taken carefully from the patellae and lower end of the femur. The anterior synovium, the posterior synovium, the fabellae, and the fibrocartilage deep to the insertion of recturs femoris were removed for histological examination

In the other groups of animals only single intra-articular injections of $C_{F}$ were used and the cartilaginous changes were studied in greater detai In one group the effect of a single injection of $\mathrm{C}_{\mathrm{F}}$ off all the knee joint cartilages was studied at differerf time intervals. At the end of the experiment eacty joint was treated as follows: after the washing procedure the semilunar cartilages and the rectus femoris fibrocartilage were first dissected, then the patella, the lower end of the femur, the upper end of the tibia, and the three fabellae were similarl dissected as free as possible from muscles anc attached tendons. To measure the total GA content of the cartilage each specimen was placed in separate tubes and digested with $2 \mathrm{ml}$ of papain (125) $\mu \mathrm{g} / \mathrm{ml}$ ) in buffer $\mathrm{pH} 6.5$ for four hours. The released GAG was then measured by the dimethylmethylene. blue (DMB) procedure. ${ }^{5}$ In the last group the response of the femoral and tibial cartilages varying doses of $C_{F}$ was examined two days afted injection. The joint cartilages were treated aœ previously described.

After excision some cartilage specimens were pu隹

\section{Clearance of ${ }^{13} 1_{1}$ labelled $C_{F}$ from rabbit knee joints}

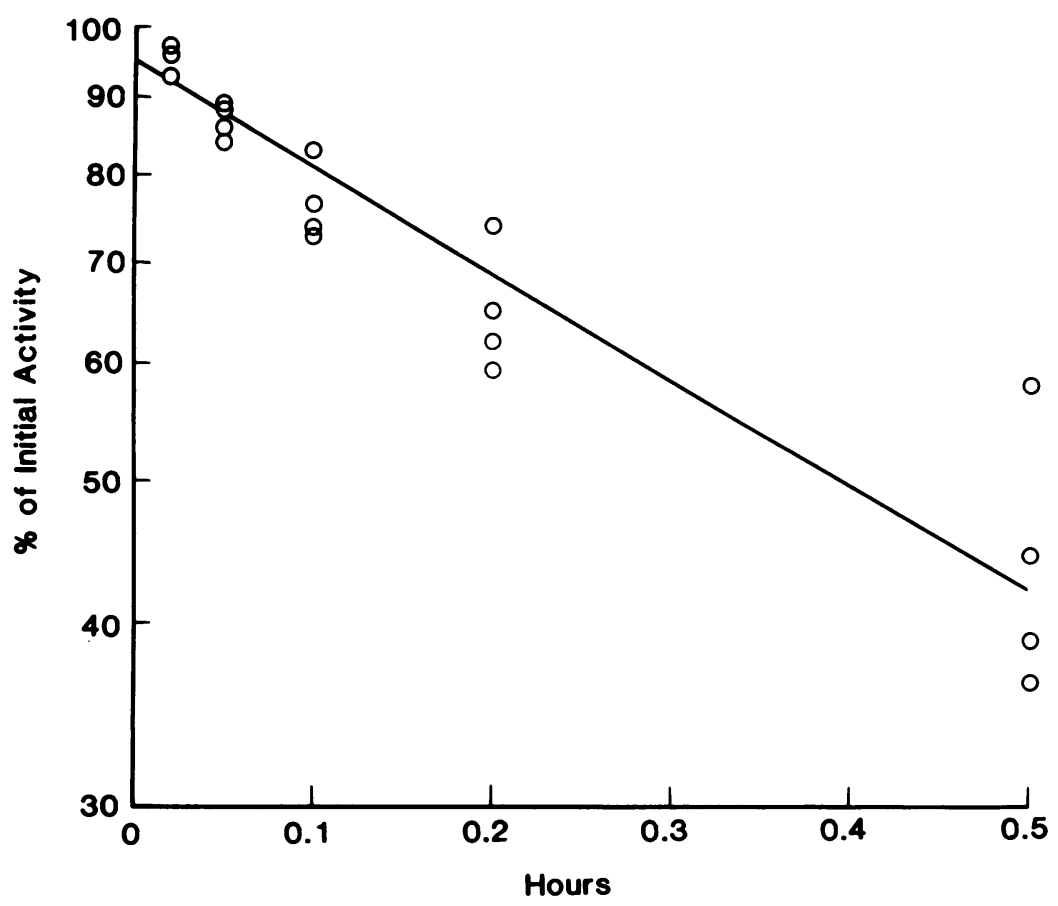

Fig. 1 The figure shows the percentage change in counts compared with the initial values $\frac{D}{2}$ from four rabbit knees over a period of $0.5 \mathrm{~h}$. 
into short term organ culture combined with a four hour $185 \mathrm{kBq}^{35} \mathrm{SO}_{4}$ pulse to determine the synthesis of proteoglycan by the cartilage. ${ }^{9}$ The synovial fluid GAG content was determined by a recent adaptation of the DMB method. ${ }^{21}$

Synovial tissues were fixed in neutral formalin, routinely processed, and stained with haematoxylin and eosin, or toluidine blue. When available articular fibrocartilages were similarly processed and stained for metachromasia by toluidine blue (bone containing specimens being first decalcified with formic acid).

\section{Results}

Radiation measurements over the knees declined exponentially with both preparations, and it was thus possible to calculate the clearance rates. Loss of radioactive counts, expressed as a percentage of the initial values for the $C_{F}$ preparation, from a group of four animals are shown in Fig. 1. The calculated half life for clearance from the joint was $0.38-0.48 \mathrm{~h}$ (the value for bovine serum albumin from the contralateral knees was $1 \cdot 86-2 \cdot 84 \mathrm{~h}$ ).

Because of the very rapid clearance of the $C_{F}$ preparation we initially decided to give daily intraarticular injections for one week in an attempt to discover whether there was any demonstrable in vivo action. The results in Table 1 show that the injection of active $C_{F}$ into the joint space caused substantial loss of GAG from the cartilage. A sixfold increase in the level of GAG was found in the synovial fluid. The ${ }^{35} \mathrm{SO}_{4}$ incorporation was significantly decreased in both the articular $(57 \%)$ and patellar cartilage (43\%). Heat treatment of the $\mathrm{C}_{\mathrm{F}}$ greatly reduced its activity in vivo. The joint cartilages not used for biochemical assays were examined histologically and showed marked loss of metachromatic material from the articular cartilages of the fabellae and the fibrocartilaginous area deep to the rectus femoris insertion (Figs 2a-f). This extensive loss of staining extended throughout both types of cartilage and was not just associated with the very small areas of pannus which were present.

The synovial reaction in the animals treated with $\mathrm{C}_{\mathrm{F}}$ showed marked synovial proliferation and extensive small roùnd cell infiltrates. Polymorphonuclear cells were found in the fluid and could be seen in the subsynovial layer. The heat inactivated preparation showed similar changes, but these were considerably less extensive, and the round cell aggregates were much smaller. The saline injected and the 'needled' controls showed no such changes.

Table 2 compares the effect of a single intraarticular injection of $\mathrm{C}_{\mathrm{F}}$ on the GAG content of different joint cartilages, at various time intervals after injection, with normal knee values from a group of six aninals. The maximal GAG loss occurred at three days. This loss was demonstrable in articular longbone cartilage, sesamoid bone cartilage, and fibrocartilage.

Synovial specimens were taken from the knees and were stained after routine processing by haematoxylin and eosin, toluidine blue, and picromallory methods. At day 1 signs of acute inflammation were present (Fig. 3a). These was synovial oedema, margination, and migration of polymorphonuclear leucocytes. Some plasma exudation between some of the subsynovial adipocytes was present. A small amount of red cell extravasation also occurred. There were some patchy areas of adipocyte hypertrophy. Some capillaries and postcapillary venules

Table 1 Effect of $C_{F}$ and partially inactivated $C_{F}$ on rabbit cartilage biochemistry in vivo

\begin{tabular}{|c|c|c|c|c|}
\hline \multirow[t]{2}{*}{ Treatment } & \multirow{2}{*}{$\begin{array}{l}\text { Articular } \\
\text { cartilage } \\
G A G \\
(\mu g / m g d r y \quad w t)\end{array}$} & \multirow{2}{*}{$\begin{array}{l}\text { Synovial } \\
\text { fluid } \\
\text { GAG } \\
(\mu g / \text { joint })\end{array}$} & \multicolumn{2}{|l|}{${ }^{35} \mathrm{SO}_{4}$ uptake } \\
\hline & & & $\begin{array}{l}\text { Patellar } \\
\text { cartilage } \\
(\text { cpm/mg dry wt) }\end{array}$ & $\begin{array}{l}\text { Articular } \\
\text { cartilage } \\
\text { (cpm/mg dry wt) }\end{array}$ \\
\hline $\begin{array}{l}\text { Active } C_{F} \\
\mathrm{p}(v \text { control }) \dagger\end{array}$ & $\begin{array}{l}50 \cdot 8(8 \cdot 75)^{*} \\
0.05(n=6) \ddagger\end{array}$ & $\begin{array}{c}70 \cdot 2(19 \cdot 3) \\
0.05 \quad(n=5)\end{array}$ & $\begin{array}{l}1295 \quad(143) \\
0.001 \quad(n=6)\end{array}$ & $\begin{array}{l}1165(24) \\
0 \cdot 01(n=6)\end{array}$ \\
\hline $\begin{array}{l}\text { Partially inactivated } C_{F} \\
\text { p }(v \text { control })\end{array}$ & $\begin{array}{l}70(10 \cdot 6) \\
\text { NS }(n=5)\end{array}$ & $\begin{array}{l}24 \cdot 8(5 \cdot 0) \\
\text { NS }(n=5)\end{array}$ & $\begin{array}{l}2224(263) \\
\text { NS }(n=5)\end{array}$ & $\begin{array}{l}2256(294) \\
\text { NS }(n=5)\end{array}$ \\
\hline Sham treated controls & $\begin{array}{l}87 \cdot 2(21 \cdot 8) \\
(n=5)\end{array}$ & $\begin{array}{l}11 \cdot 25(7 \cdot 8) \\
(n=4)\end{array}$ & $\begin{array}{l}2280(511) \\
(n=5)\end{array}$ & $\begin{array}{l}2683(711) \\
(n=5)\end{array}$ \\
\hline
\end{tabular}

$\mathrm{C}_{\mathrm{F}}$ and heat inactivated ( $10 \%$ active) $\mathrm{C}_{\mathrm{F}}$ was injected intra-articularly into six rabbits. At one week the knee joints were analysed for cartilage GAG content, uptake of ${ }^{35} \mathrm{SO}_{4}$ into cartilage GAG, and synovial fluid GAG.

${ }^{*}$ Values in the table are means and standard errors (SEM).

†Significance of the probability value $(\mathrm{p})$ was tested with Student's $t$ test.

$\ddagger \mathrm{n}=$ number of knees. 
showed swollen hypertrophic initimal cells. These changes had become even more marked by the second day. In addition, a surface fibrinous exudate occurred in some areas, and an occasional small round cell accumulation was present in the inter-

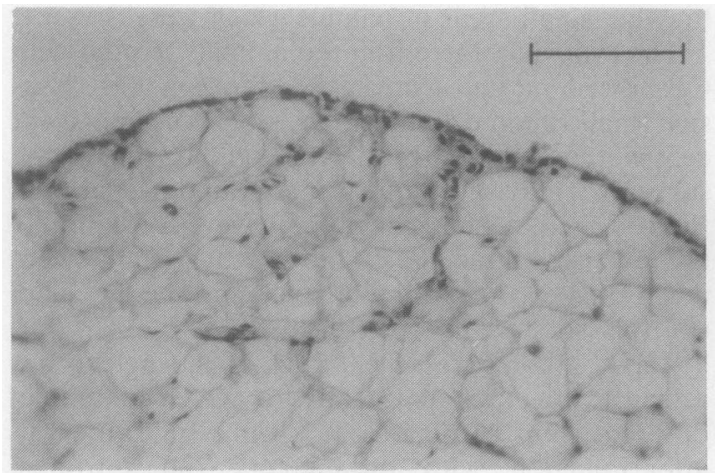

Fig. 2a

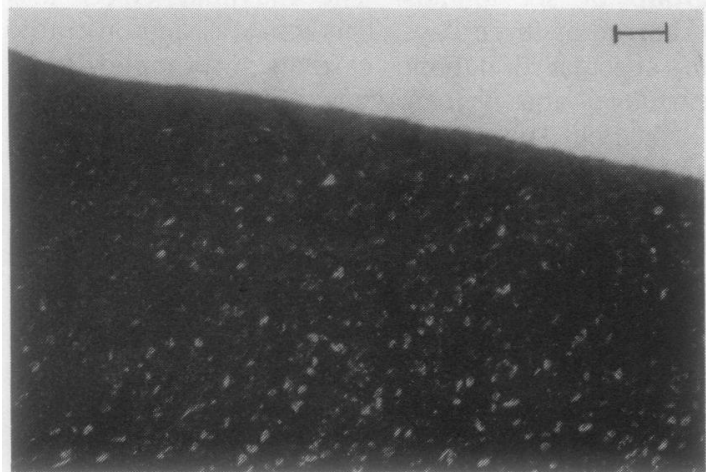

Fig. 2c

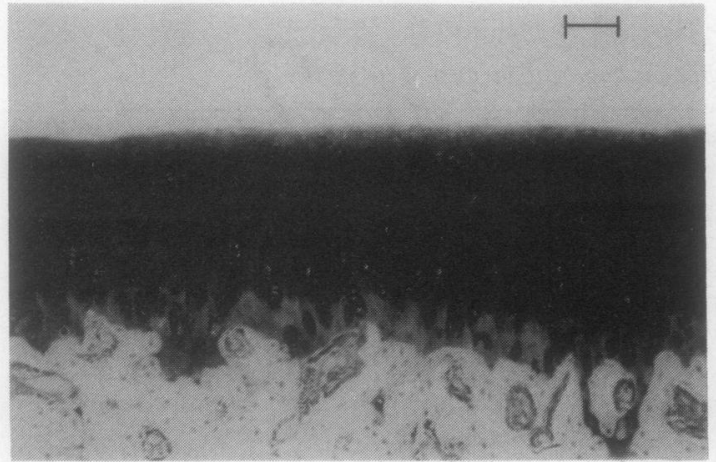

Fig. 2e face. So intense did the polymorphonuclear leucocyte migration become that rings of them werew present around fat globules after escaping from the interadipocyte capillaries.

By the third day the pathological changes reached

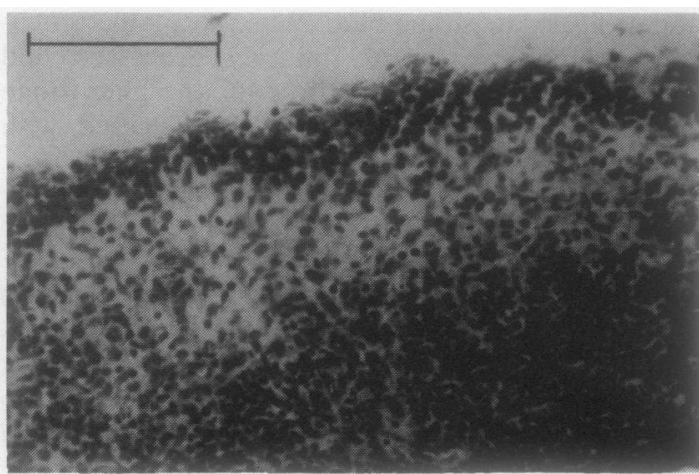

Fig. 2b

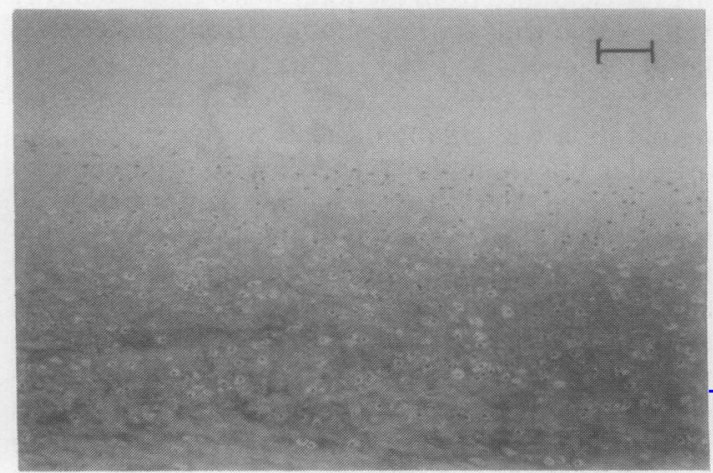

Fig. 2d

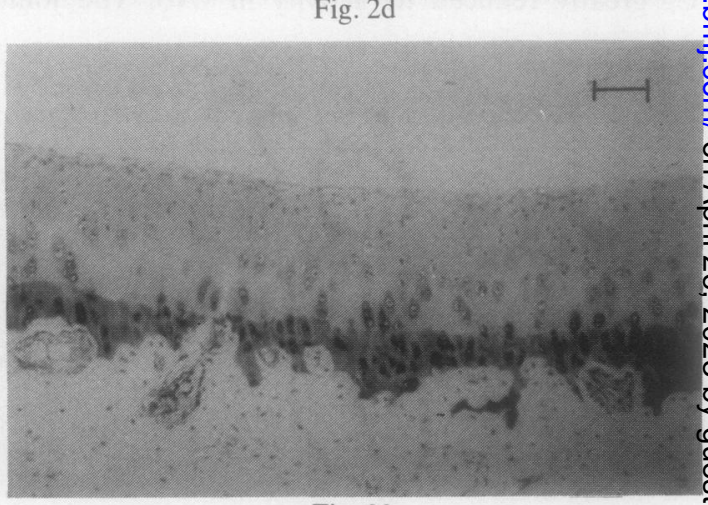

Fig. $2 \mathrm{f}$

Fig. 2 (a) Normal synovial membrane. (b) $C_{F}$ preparation: synovial hypertrophy and subsynovial small round cell filtration. (c) Normal fibrocartilage. Dense metachromatic staining. (d) $C_{F}$ preparation: similar area to that shown in (c). Marked loss of metachromasia. (e) Normal fabella articular cartilage. Dense metachromatic staining. $(f) C_{F}$ preparation: similar area to that shown in (e). Marked metachromatic loss. All stained with toluidine blue and photographed on Ilford Pan F with a Balzers B40 $\lambda 542$ filter. Bars indicate $0 \cdot 1 \mathrm{~mm}$. 
Table 2 Effect of $C_{F}$ on cartilage proteoglycan $(G A G)$ at different time intervals

\begin{tabular}{|c|c|c|c|c|c|c|}
\hline \multirow[t]{2}{*}{ Site } & \multicolumn{6}{|c|}{ Time after intra-articular injection (days) } \\
\hline & 0 & 1 & 2 & 3 & 6 & 9 \\
\hline Femur & $6165(623)$ & 5466 & 3768 & 2836 & 2335 & 2900 \\
\hline Tibia & $6965(676)$ & 4281 & 3665 & 2356 & 3001 & 3192 \\
\hline Patella & 1793 (101) & 1686 & 678 & 472 & 696 & 604 \\
\hline Fabellae & $657 \quad(20)$ & 211 & 156 & 159 & 165 & 189 \\
\hline Fibrocartilages & $2367 \quad(87)$ & 1762 & 698 & 1248 & 1096 & 682 \\
\hline Total/knee & 17947 & 13406 & 8965 & 7071 & 7293 & 7567 \\
\hline
\end{tabular}

The values ( $\mu \mathrm{g} \mathrm{GAG/tissue)} \mathrm{were} \mathrm{obtained} \mathrm{by} \mathrm{papain} \mathrm{digestion} \mathrm{and} \mathrm{are} \mathrm{given} \mathrm{for} \mathrm{the} \mathrm{whole} \mathrm{cartilage} \mathrm{(SEM).} \mathrm{The} \mathrm{remaining} \mathrm{values} \mathrm{are} \mathrm{the}$ mean values from both knees of animals who had previously received their intra-articular injections of $\mathrm{C}_{\mathrm{F}}$ at the time intervals indicated.

their maximum (Fig. 3b). In addition to more surface fibrin, and early signs of its incorporation into the synovium by overgrowth of surface synovial lining cells, which became hypertrophic, numerous foci of small round cells wefe present below the surface, together with many plasma cells. The picromallory stain showed an increase in collagen staining immediately below the surface, and this was accompanied by a concomitant disappearance of adipocyte lipid.

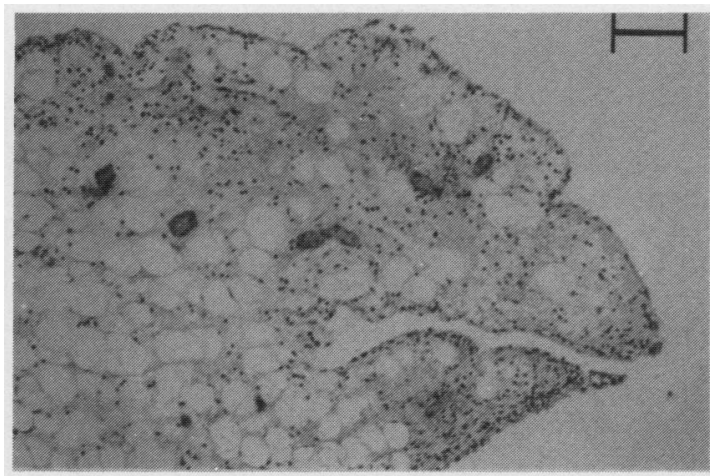

Fig. 3a

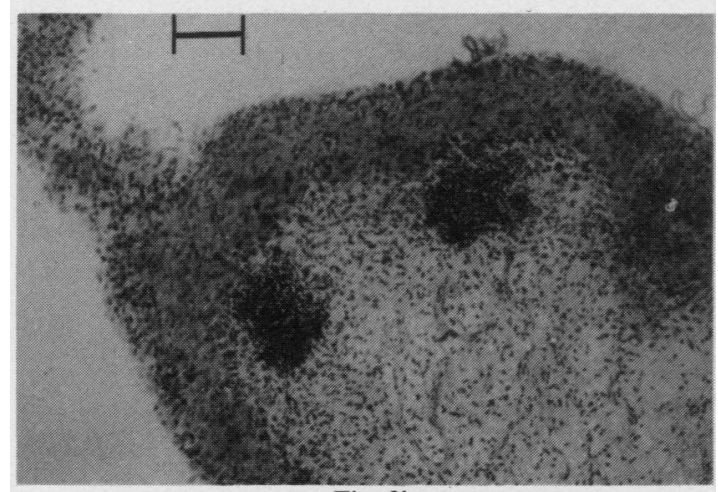

Fig. $3 b$
Nine days after injection a dispersal of the pathological changes had occurred (Fig. 3c). The only abnormalities present were subsynovial fibrosis, the occasional small round cell focus, scattered small areas of adipocyte hypertrophy, fibrin organisation, and some increase in collagen fibres around small arteries. Polymorphonuclear leucocytes were greatly reduced in number. The effect of a concentration range of $\mathrm{C}_{\mathrm{F}}$ on the histological changes in the synovium was examined two days

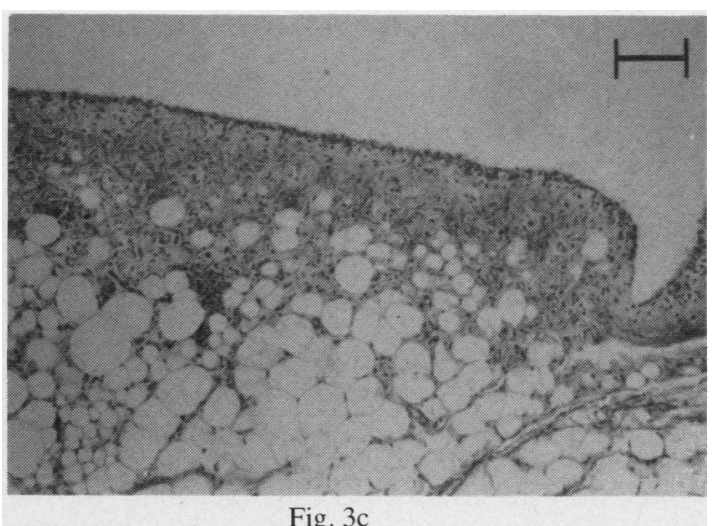

Fig. 3 (a) Synovium one day after injection of $C_{F}$. Oedema, exudation, vascular engorgement are present, and polymorphonuclear $(P M N)$ diapedesis is beginning. (b) Synovium three days after injection of $C_{F}$. Round cell foci are present. Dark staining band in subsurface layer is due to fibrin deposition. Many inflammatory PMN cells, macrophages, and plasma cells are present in the synovium. Some loss of adipocyte fat and concomitant increase in collagen has occurred in the deeper layers. (c) Synovium nine days after injection of $C_{F}$. Major factors are the amount of subsurface collagen with loss of fat, and a great diminution in the number of inflammatory cells. All picromallory stained and photographed on Ilford Pan F with a Balzers B40 $\lambda 592$ filter. Bars indicate $0.1 \mathrm{~mm}$. 
Percentage loss of glycosaminoglycan (GAG) with increasing dosage of catabolin at two days after injection

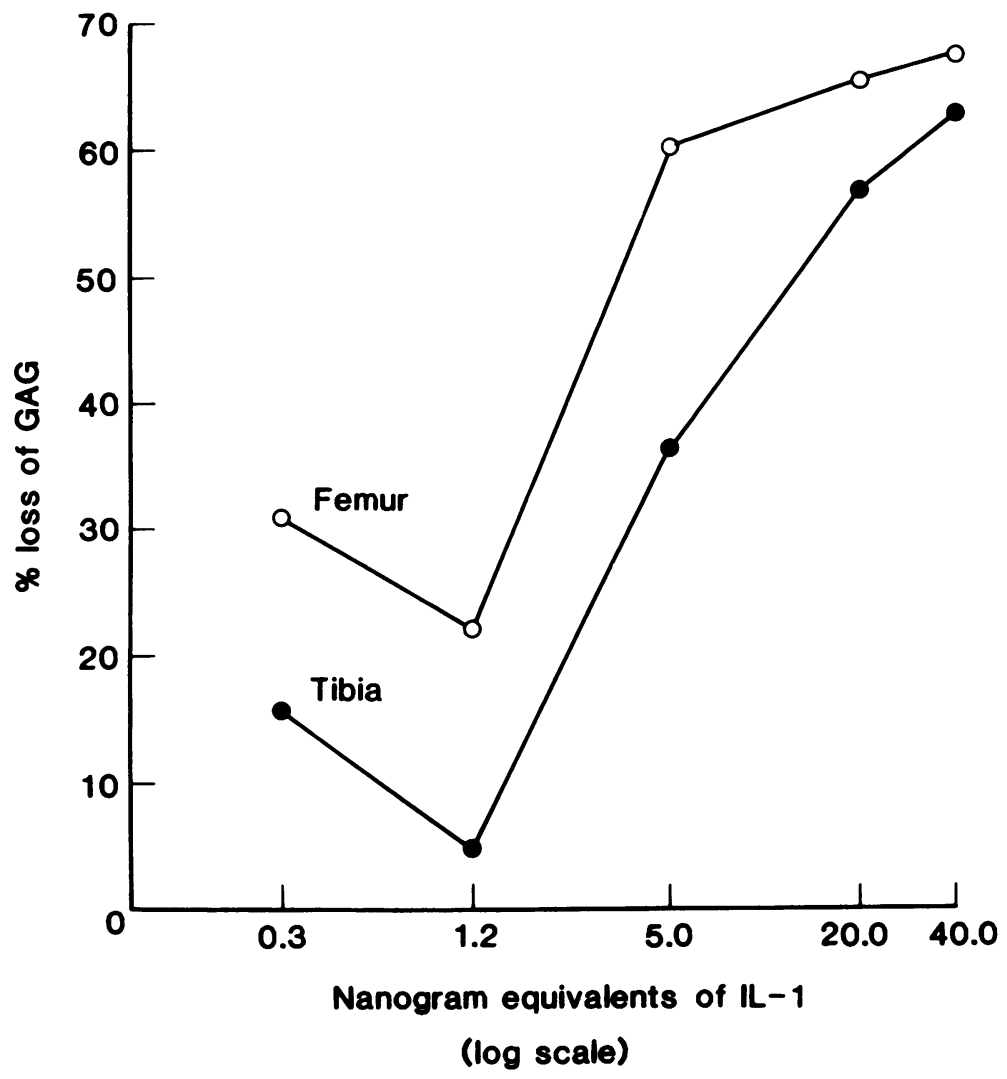

Fig. 4 The values in the figure are the means of both knees for the femur or tibia compared with the means of six normal rabbit knees and expressed as a percentage change. Each knee of the treated animals received the indicated equivalents of porcine ILI $\alpha$.

after injection. At the high dose (activity equivalent to $40 \mathrm{ng}$ of IL1 $\alpha$ protein) these were similar to those described above. Equivalent does of $5 \mathrm{ng}$ and below showed only patchy vascular engorgement, synovial hypertrophy, and subsurface fibrosis. Very few polymorphonuclear leucocytes were seen, but scattered areas of adipocyte hypertrophy were still noticeable. Some localised clearly abnormal areas were found down to a dose level of $0.3 \mathrm{ng}$. The cartilaginous changes in GAG content over the same dose range are shown in Fig. 4.

\section{Discussion}

Experiments using the partially purified synovial catabolin/IL1 $\left(\mathrm{C}_{\mathrm{F}}\right)$ were thought to be worthwhile for two reasons. Firstly, it is known that purification to homogeneity of the $\alpha$ and $\beta$ forms of IL1 leads to the selective loss of materials active in the cartilage bioassay. Results of a recent unpublished study bis $\mathrm{Qi}$ and Dingle showed that synovial tissue contain $\mathrm{C}_{\mathrm{F}}$-like activity of both higher and lower relative molecular mass from the secreted IL1 which has been purified to homogeneity. It was though? preferable in this initial study to investigate the action in vivo of as wide a range as possible of active cytokine material produced by synovial tissue and related to the catabolin/IL1 family. If activity were् found in vivo the purified separate gene products ( $क$ and $\beta$ IL.1) and other related cytokines of differen physical properties could be investigated.

Secondly, the cost in both man hours and maœ terials in preparing a substantial quantity of purified material when it was not known whether or not $\mathrm{C}_{\overline{0}}^{-}$ would act on joint tissues in vivo was prohibitive $\mathbb{\mathbb { D }}$

The daily injection of the dose used in the first experimental group (Table 1) was prompted by the very rapid clearance of the preparation as shown int 
Fig. 1. The extensive changes found at three days suggest that substantially lower doses will be sufficient in future work.

The action of both $\mathrm{C}_{\mathrm{F}}$ and the homogeneous porcine leucocyte IL1 $\alpha$ on cartilage in organ culture has been well characterised. ${ }^{5-912}$ Both preparations cause extensive loss of proteoglycan, and later collagen, from the cartilage explant, and proteoglycan appears in the culture medium. There is also substantial inhibition of proteoglycan and collagen synthesis, and histologically extensive loss of metachromasia is observed. It is clear from the experiments reported in this paper that the action of $\mathrm{C}_{\mathrm{F}}$ in vivo is similar to its action in vitro on cartilage in organ culture, but we cannot preclude the possibility that a secondary action(s) mediated via the synovium also plays a part in the cartilage catabolism. The remarkable transience of the induced extensive synovitis is being further investigated in greater detail.

The correlation between synovial fluid measurement of GAG release and the other parameters of catabolin/IL1 action is encouraging. The application of this method of estimation of synovial fluid GAG has not been used in animals before, and its application to human synovial fluid is being actively pursued. $^{22}$

Although the experiments reported above are essentially preliminary in nature, they do indicate for the first time that a synovial cytokine preparation will cause joint damage in vivo, and this makes determination of its effect worthwhile, using pure materials, dose and time curves, and tissue and cellular localisation with the radiolabelled homogeneous IL1 $\alpha$ which is now available. Thus it seems likely that much of the theory of the action of these messengers, which has been extrapolated from organ culture work, may be correct. Although it must be emphasised that these animal experiments do not prove that cytokines are partially or totally responsible for arthritic damage in humans, nevertheless their in vivo effects suggest that they may well be implicated in some aspects of pathogenesis.

Further experiments to determine the physiological factors which modify cytokine function in vivo are urgently needed. The application of such knowledge to maintenance of joint tissue function in patients with osteoathritis or rheumatoid arthritis could prove of value.

This research was supported by the Arthritis and Rheumatism Council and the Medical Research Council.

\section{References}

1 Dingle J T. Recent studies on the control of joint damage: the contribution of the Strangeways Research Laboratory. Ann Rheum Dis 1979; 38: 201-14.

2 Dingle J T, Saklatvala J. In: Dingle J T, Gordon J L, eds.
Cellular interactions. Amsterdam, New York. Oxford: Elsevier. North Holland Biomedical Press, 1981: 281-9.

3 Decker R S. Dingle J T. Cardiac catabolic factors: the degradation of heart valve intercellular matrix. Science 1982: 215: $987-9$.

4 Brown M F. Hazleman B L. Dingle J T. Dandy D J, Murley A H G. Production of cartilage degrading activity by human synovial tissues. Ann Rheum Dis 1987: 46: 319-23.

5 Dingle J T, Saklatvala J, Hembry R M. Tyler J, Fell H B. Jubb R. A cartilage catabolic factor from synovium. Biochem J 1979: 184: $177-80$.

6 Dingle J T. Catabolin-a cartilage catabolic factor from synovium. Clin Orthrop 1981; 156: 219-31.

7 Saklatvala J, Sarsfield S J, Pilsworth L M C. Characterization of proteins from human synovium and mononuclear leucocytes that induce resorption of cartilage protecglycan in vitro. Biochem J 1983; 209: 337-44.

8 Saklatvala J, Sarsfield S J, Townsend Y. Pig interleukin 1. Purification of two immunologically different leukocyte proteins that cause cartilage resorption. lymphocyte activation and fever. J Exp Med 1985; 162: 1208-22.

9 Dingle J T. The effect of synovial catabolin on cartilage synthetic activity. Connect Tissue Res 1984; 12: 277-86.

10 Tyler J. Articular cartilage cultured with catabolin (pig interleukin 1) synthesizes a decreased number of normal proteoglycan molecules. Biochem $J$ 1985; 227: 869-78.

11 Saklatvala J, Pilsworth L M C. Sarsfield S J, Gavrilovic J, Heath J. Pig catabolin is a form of interleukin 1. Cartilage and bone resorb, fibroblasts make prostaglandin and collagenase. and thymocyte proliferation is augmented in response to one protein. Biochem J 1984; 224: 461-6.

12 Jasin $\mathrm{H} \mathrm{E}$, Dingle $\mathrm{J}$ T. Human mononuclear cells factors mediate cartilage degradation through chondrocyte activation. J Clin Invest 1981; 68: 571-81.

13 Dayer J M, Stephenson M L. Schmidt E. Karge W. Krane S M. Purification of a factor from human blood monocyte macrophages which stimulates the production of collagenase and prostaglandin $E_{2}$ by cells cultured from rheumatoid synovial tissues. FEBS Lett 1981; 124: 253-6.

14 Russell R G G, McGuire M K. Meats J E, Elsworth N M. Beresford J. Intercellular messengers in joint tissues in rheumatoid arthritis. How disturbed control mechanisms may contribute to tissue destruction and repair. Scand J Rheumatol [Suppl] 1981; 40: 75-87.

15 Gowen M, Wood D D, Ihrie E J, Meats J E, Russell R G G. Stimulation by human interleukin 1 of cartilage breakdown and production of collagenase and proteoglycanase by human chondrocytes but not by human osteoblasts in vitro. Biochim Biophys Acta 1984; 797: 186-93.

16 Oppenheim J J, Gery I. Interleukin 1 is more than an interleukin. Immunol Today 1982; 3: 113-9.

17 Heath J K, Saklatvala J, Meikle M C. Atkinson S J, Reynolds J J. Cytokine-mediated bone resorption. Calcif Tissue Int 1984; 36 (suppl 2): 7

18 Dingle J T, Qi E. Intracellular catabolin like activity in cultured tissue. In Vitro 1983; 19: 892-6.

19 Markwell M A K. A new solid state reagent to iodinate proteins: 1. Conditions for the efficient labelling of antiserum. Anal Biochem 1982; 125: 427-32.

20 Bard D R, Knight C G, Page Thomas D P. The retention and distribution in the rabbit knee of a radionuclide complexed with a lipophilic chelator in liposomes. Clin Exp Rheumatol 1983; 1: 113.

21 Farndale R W, Buttle D J, Barrett A J. Improved quantitation and discrimination of sulphated glycosaminoglycans by use of dimethylmethylene blue. Biochim Biophys Acta (in press).

22 Dingle J T, Page Thomas D P. Hazleman B L. The role of cytokines in arthritic diseases: in vitro and in vivo measurements of cartilage degradation. 2nd World conference on inflammation. Geneva: Bioscience Ediprint (in press). 